\title{
Pelatihan Pembuatan Minuman Herbal Modern dalam Kemasan Siap Minum di Puskesmas Mojolangu
}

\author{
Training on Making Modern Herbal Drinks in Packaging Ready to Drink at the Mojolangu \\ Health Center
}

Amaliyah Dina Anggraeni ${ }^{*}$
Kurnia Putri Utami ${ }^{*}$
Nungki Marlian Yuliadarwati ${ }^{2}$
1Department of Pharmacy, Universitas
Malang, Malang, East Java, Indonesia
2Department of Physiotherapy,
Universitas Malang, Malang, East
Java, Indonesia
*email: amaliyah@umm.ac.id
Kata Kunci
Minuman
Herbal Modern
Puskesmas Mojolangu
Keywords:
Drink
Herbal Modern
Mojolangu Health Center
Received: November 2019
Published: June 2020

\begin{abstract}
Abstrak
Pelatihan pembuatan minuman herbal modern dalam kemasan telah dilakukan di puskesmas mojolangu, kota malang. Tujuan dari pelatihan pembuatan minuman herbal modern adalah memberikan keterampilan kepada mitra agar dapat membantu meningkatkan perekonomian keluarga melalui ekonomi kreatif. Sehingga produk yang dihasilkan dapat dipasarkan di sarana publik seperti sekolah serta warung dan toko kelontong. Luaran dari kegiatan pelatihan adalah memberikan solusi terhadap permasalahan yang dihadapi masyarakat di desa mitra dengan cara terpadu sehingga dapat meningkatkan nilai perekonomian masyarakat setempat. Disamping itu, ada nilai luhur yang ingin disampaikan oleh penulis yakni agar jamu lebih dikenal secara global dengan tidak mengurangi khasiatnya. Pelatihan pembuatan minuman herbal modern bisa digunakan sebagai bahan produk/pengembangan industri oleh mitra sebagai pelaku usaha. Penerbitan sertifikat yang diberikan kepada warga yang mengikuti pelatihan sebagai bentuk apresiasi mereka sudah ikut berpartisipasi dalam pelatihan pembuatan minuman herbal modern, peningkatan pengetahuan, kemampuan skill, dan rasa percaya diri kader puskesmas di bidang pengobatan tradisional dalam menanggulangi kesehatan di masyarakat dengan cepat dan tepat. Kegiatan pengabdian ini akan dimasukkan menjadi pengalaman yang tidak hanya berguna bagi masyarakat mitra, tetapi juga bagi keluarga terdekat dan lingkungan sekitar.
\end{abstract}

\begin{abstract}
Training on making new herbal drinks in containers has been carried out at the Mojolangu Health Center, Malang city. The aim of the training on making new herbal drinks is to provide skills to partners in order to help improve the family economy through the creative economy. So the products produced can be marketed in public facilities such as schools and food stalls and grocery stores. The output of the training activities is to provide solutions to problems faced by the community in partner villages in an integrated manner to increase the economic value of the local community. Besides that, there is a noble value to be conveyed by the author, namely that herbal medicine is better known globally by not reducing its usefulness. Training on making new herbal drinks can be used as product ingredients/industrial development by partners as entrepreneurs. Issuance of certificates given to residents who took part in training as a form of appreciation, they have participated in training in making new herbal drinks, increased knowledge, skills, and confidence of health center cadres in the field of traditional medicine in tackling health in the community quickly and accurately. These community service activities will include experiences that are not only useful for the partner community but also the immediate family and the surrounding environment.
\end{abstract} the CC-BY-SA License (http://creativecommons.org/licenses/by-sa/4.0/). DOI: https://doi.org/10.33084/pengabdianmu.v5i3.1126 


\section{PENDAHULUAN}

Produk Herbal adalah salah satu bagian peningkatan ekonomi kreatif, merupakan sebuah konsep di era ekonomi baru yang mengintensifkan informasi dan kreativitas dengan mengandalkan ide dan pengetahuan dari sumber daya manusia sebagai faktor produksi yang utama. Konsep ini biasanya akan didukung dengan keberadaan industri kreatif yang bertujuan untuk meningkatkan perekonomian (Mukhlish, 2018). Keberhasilan perekonomian merupakan cita-cita suatu bangsa yang terlihat dari peningkatan taraf hidup masyarakat, begitu juga dengan Indonesia yang merupakan negara meritim yang mempunyai pontensi perekonomian yang sangat tinggi yang didukung oleh berlimpahnya kekayaan hayati yang baraneka ragam (Ingratubun \& Sombolayuk, 2018).

Kekayaan hayati berupa keaneka ragaman tumbuhan, mulai dari tumbuhan tingkat rendah hingga yang telah di manfaatkan oleh masyarakat yang berupa obat tradisional (jamu) dan minuman kesehatan herbal (Jo, 2016). Indonesia memiliki 30.000 spesies tanaman, dari spesies tanaman tersebut lebih dari 3300 tanaman merupakan yang mempunyai khasiat yang telah di manfaatkan oleh masyarakat sebagai obat tradisional (jamu) (Jumiarni \& Komalasari, 2017). Peningkatan ekonomi juga didukung sikap atau perilaku masyarakat dan budaya masyarakat indonesia adalah kehidupan konsumtif, masyarakat Indonesia mempunyai respon baik mengenai konsumsi jamu yang sangat melekat mendarah daging, bahkan menjadi budaya masyarakat Indonesia (Septiana, 2019).

Data yang berasal dari Mendagri pada tahun 2012 yang menyatakan tingkat konsumsi minuman herbal, bahwa telah terjadi preubahan respon konsumsi minuman herbal, hal ini dapat dilihat dari presentase berikut, minuman herbal cair terdapat $51 \%$, puyer atau serbuk $40 \%$, dan pil/kapsul 9\%. Bentuk minuman herbal yang paling di minati adalah cair sebesar 59\%, puyer/serbuk sebesar 30\% dan pil/kapsul sebesar 11\% (Ismono et al., 2018). Dari tingkat kepuasan dalam mengkonsumsi jamu adalah sebagai berikut, konsumen mengaku puas dan mengutamakan minum jamu sebesar 81\%, sementara $11 \%$ hanya menganjurkan kepada orang lain untuk mengkonsumsi jamu dan sisanya masih mengutamakan obat-obatan dari farmasi. Berdasarkan hasil temuan menunjukkan bahwa industri minuman herbal harus melakukan managemen kepuasan dan memberikan pengetahuan terhadap pentingnya konsumsi produk minuman herbal (Andriati \& Wahjudi, 2016).

Salah satu produk minuman herbal modern yang telah dikenal masyarakat adalah sediaan serbukjamu. Produk jamu tersebut berbentuk minuman instan dan serbuk sehingga bersifat praktis dan cepat dalam penyajian serta memiliki daya simpan yang cukup lama. Minuman herbal modern di buat dengan menggunakan ekstrak tumbuhan (Sukmawati \& Merina, 2019). Minuman herbal modern selain berbentuk minuman instan berupa sirup dan serbuk. Kedua jenis minuman tersebut dapat di buat dari tanaman obat keluarga atau yang banyak di jumpai seperti: jahe, kunyit, lemgkuas, temulawak, sereh, bunga rosella. Sementara minuman instan yang berasal dari empon-empon dengan bahan utama jahe dapat menambah nafsu makan, menjaga fungsi hati, mencegah peradangan, mencegah kanker dan bersifat anti oksidan (Ismono et al., 2018)

Pembuatan minuman alternatif yang berupa serbuk jahe, temulawak, serbuk secang, dan serbuk kejibeling dapat menjadi pilihan untuk stamina, temulawak kunyit dan kencur dapat meningkatkandaya tahan tubuh dan nafsu makan (Moehady, 2015). Minuman herbal modern dalam kemasan siap minum yang sudah diolah selain mengandung gizi juga mengandung senyawa bioaktif yang bersifat melancarkan peredaran darah, menjaga 
fungsi hati, anti inflamasi, anti kanker dan antioksidan. Apabila informasi tetang baiknya kandungan dalam minuman herbal kepada konsumen maka minuman herbal ini sangat bangus untuk meningkatkan finansial atau pendapatan yang besar (Khamidah et al., 2017; Arifin et al., 2017).

Kader kesehatan puskesmas Mojolangu yang memiliki wawasan dan jiwa kewirausahaan, dapat menjadi wirausahawan dengan memproduksi minuman herbal modern dalam kemasan siap minum. Usaha ini memiliki prospek untuk meningkatkan penghasilan dan membuka lapangan pekerjaan. Hal ini didukung dengan adanya pekarangan yang ditanami TOGA di sekitar tempat tinggal kader mitra sehat puskesmas Mojolangu (Rachmawati et al., 2018).

Berdasarkan paparan latar belakang, maka permasalahan yang diusulkan melalui kegiatan pengabdian kepada masyarakat adalah bertujuan untuk memberikan keterampilan yang memiliki manfaat ekonomi bagi kader puskesmas Mojolangu dengan penanaman jiwa wirausaha, managemen usaha, teknik pengemasan, pemasaran produk minuman herbal modern dalam kemasan siap minum.

\section{METODOLOGI}

\section{Alat dan bahan}

Alat yang digunakan dlam program pengadian inia antara lain Ember, Tampah, Blender, Pisau, Parutan, Panci, Wajan, Saringan, Kompor gas, Tabung gas, Oven, Pengaduk kayu, Timbangan, Gelas ukur, Gelas plastik, Plastik makanan, Botol 250 ml, Kertas Label, Sealer.

Bahan yang digunakan untuk pembuatan minuman herbal adalah Daun Asam, Kunyit, Asam Jawa, Kencur, Beras, Jahe, Gula Pasir, Gula Aren, Gula Merah, Garam, Cengkeh, Daun cengkeh, Jeruk Nipis, Madu TJ, Daun Pandan, Kayu Secang, Biji Pala, Daun Pala Kering, Serai, Temulawak, Daun sirih, Kayu manis, Lidah Buaya.

\section{Metode pelaksanaan}

Kegiatan pengabdian ini menggunakan metode participatory approach untuk mengatasi permasalahan yang dialami oleh masyarakat di desa mitra. Artinya melibatkan mitra secara aktif dalam proses pelatihan dan pengolahan usaha dari pembuatan minuman herbal kemasan. Metode pelaksanaan pada kegiatan pengabdian ini dapat dilihat pada Gambar 1.

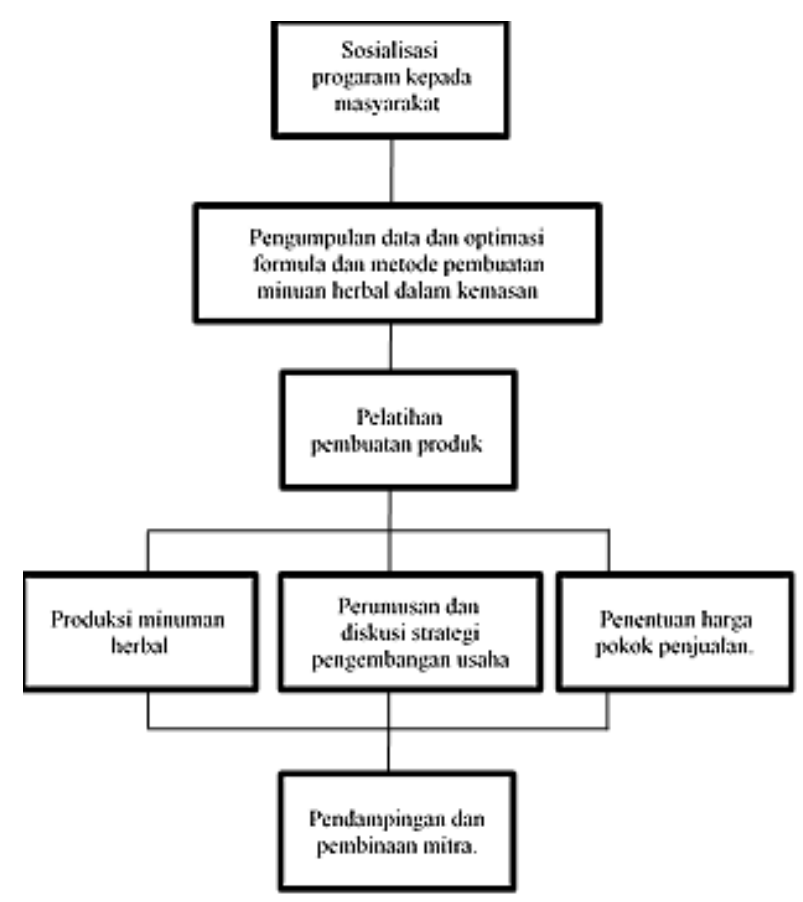

Gambar 1. Kerangka Operasional Pelaksanaan Kegiatan Pengabdian

Kerangka operasional di atas menjelaskan bahwa untuk merealisasikan program agar sesuai dengan target luaran, maka hal pertama yang dilakukan adalah melakukan sosialisasi kepada masyarakat sasaran terkait program pengembahan usaha ekonomi kreatif dengan mengadakan pelatihan pembuatan minuman herbal dalam kemasan. Pada tahap ini pengusul dan masyarakat sasaran menyamakan pemahaman antara satu dengan yang lain terkait hasil (outcome) yang nantinya akan didapatkan. Sehingga, diharapkan masyarakat sasaran dapat terlibat secara aktif dalam kegiatan ini. Kemudian, dilakukan pengumpulan data dan survei (optimasi) terkait metode pembuatan 
berbagai varian minuman herbal yang akan diproduksi sehingga ditemukan formula yang tepat dengan memperhatikan kualitas dan keamanan produk. Tahap ketiga yaitu melakukan pelatihan pembuatan minuman herbal kemasan berbasis komoditas lokal. Produksi dilakukan setelah tahapan ini, dilanjutkan dengan pengemasan dan pemberian label yang komunikatif. Tahap keempat dilakukan diskusi tentang strategi pengembangan usaha produksi minuman herbal dalam kemasan. Kemundian dilakukan analisis kelayakan usaha industri rumahan secara sederhana dan penentuan harga pokok penjualan. Tahap akhir yaitu melakukan pendampingan teknis monitoring dan pembinaan kelompok untuk meninjau keberlanjutan usaha ini.

Sehingga dapat disimpulkan bahwa kontribusi desa mitra diharapkan dapat menjadi perantara tim pelaksana dengan kader pengobatan tradisional puskesmas Mojolangu untuk menjalankan tujuan kegiatan pengabdian ini. Mitra diharapkan dapat mengumpulkan kelompok masyarakat melalui kedekatan hubungan mitra dengan masyarakat setempat. Mengkomunikasikan tujuan kegiatan yaitu peningkatan pendapatan masyarakat mitra melalui kegiatan ekonomi kreatif. Mengkomunikasikan tujuan kegiatan, agenda dan lokasi pelaksanaan kegiatan pelatihan. Memberi masukan bagi kesempurnaan kegiatan sesuai dengan kebutuhan dan karakteristik mitra.

\section{HASIL DAN PEMBAHASAN}

Program pengabdian masyarakat menyasar sekelompok ibu-ibu yang bertempat tinggal di Kawasan Mojolangu dan menjadi binaan puskesmas Mojolangu. Kader ini telah memiliki kebun toga yang dibudidayakan oleh masyarakat setempat. Hanya saja belum banyak dilakukan pengembangan terhadap tanaman yang telah dibudidayakan tersebut. Dengan berbekal potensi bahan alam dan perkumpulan yang sudah ada, pengusul memilih sebagai mitra untuk dapat dberi pembimbingan dalam kegiatan pengabdian masyarakat yaitu pembuatan minuman herbal.

Tahapan awal pelaksanan program pengabdian masyarakat yaitu melakukan koordinaasi dengan pihak puskesmas sebagai koordinator pembinaan kader masyarakat di daerah Mojolangu. Selanjutnya melakukan pertemuan lanjutan terkait pertemuan untuk membahas teknis pembimbingan dan sosialisasi pembuatan minuman herbal modern. Dimulai dari jadwal sampai dengan peralatan apa saja yang dibutuhkan serta bahan yang sekiranya masih belum tersedia. Kegiatan sosialisasi dan pembimbingan pembuatan minuman herbal modern dilaksanakan antara tim pengusul dengan kader puskesmas dengan antusias. Kegiatan ini melibatkan peran serta aktif mitra atau peserta program pengabdian masyarakat sehingga dapat berkjalan dengan sangat baik antara tim pengusul dan kader puskesmas.

Pendampingan pemilhan bahan baku, proses pengelolahan minuman herbal dan pengemasan produk pada wadah secara higienis

Peserta program pengabdian masyarakat mulanya diberikan pengetahuan secara teoritis terkait prosedur pembuatan minuman herbal modern yang baik dengan memperhatikan pilihan kemasan yang aman dan higenis. Selain itu juga dierikan formula baku pembuatan minuman tradisional berdasarkan buku literatur yang telah dikumpulkan oleh tim pengusul berdasarkan khasiat secara empiris dilakukan oleh beberapa daerah di Indonesia. Pemberian materi dilakukan dengan metode ceramah dan diskusi. Peserta dapat melontarkan pertanyaan ditengah pemberian materi. Hal ini dilakukan dengan tujuan agar peserta dapat memahami materi yang sedang diberikan. 
Kegiatan selanjutnya adalah pemaparan cara pembuatan desain kemasan pada wadah yang akan digunakan pada saat proses pengemasan produk. Berdasarkan kegiatan peningkatan ilmu pengetahuan dan wawasan tentang minuman obat herbal modern peserta nampak sangat antusias mengikuti acara pertama tersebut. Hal ini dibuktikan dengan banyaknya respon pertanyaan yang diajukan oleh peserta seputar pembuatan minuman herbal berdasarkan pengalaman yang pernah dilakukan dan tips khusus pada saat proses produksi.

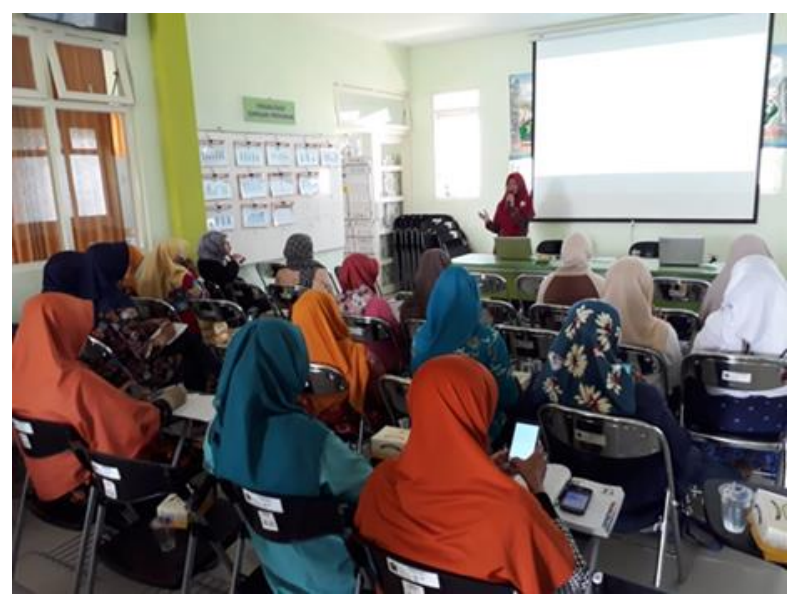

Gambar 2. Kegiatan Edukasi Minuman Herbal dengan Warga Mitra

\section{Praktek cara pembuatan minuman herbal modern}

Kegiatan pertama yang dilakukan adalah menyiapkan alat dan bahan yang akan digunakan. Tahapan ini dibantu oleh mahasiswa yang dilibatkan untuk melancarkan kegiatan program pengabdian kepada masyarakat. Selanjutnya adalah praktik pembuatan minuman herbal dengan metode pendampingan dan diskusi. Artinya pada saat pembuatan pemateri juga menjelaskan setiap tahapan sesuai dengan prosedur yang benar dan langsung dilakukan sesi tanya jawabjika dalam proses pembuatan terdapat permasalahan teknis. Peserta juga dihimbau untuk memperhatikan kebersihan peralatan yang digunakan serta simplisia segar sebagai bahan baku harus dalam kondisi bersih dan telah dicuci sebelumnya. Kemudian kegiatan dilanjutkan dengan pengemasan dan pelabelan produk minuman herbal.

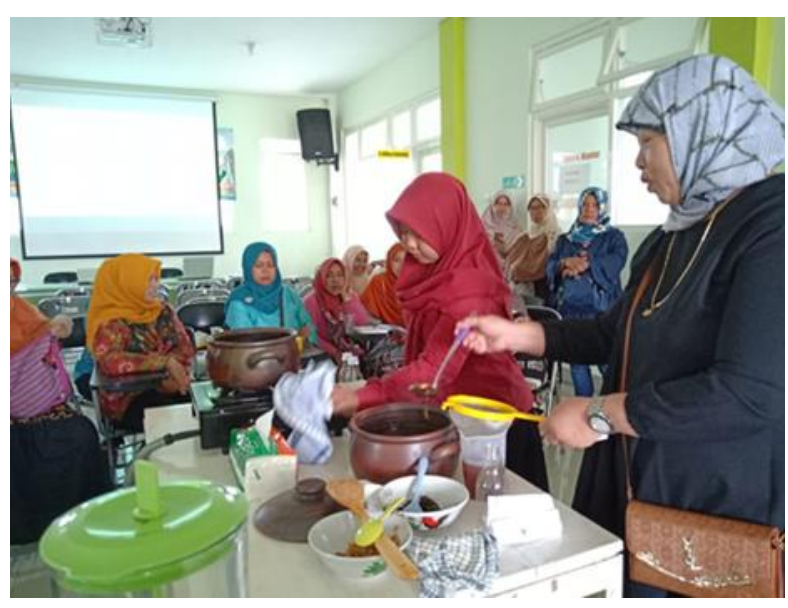

Gambar 3. Praktek Pembuatan Minuman Herbal

Peserta pelatihan diberikan kesempatan untuk dapat membuat sendiri salah satu produk minuman herbal yang telah dicontohkan sebelumnya. Hal ini diharapkan dapat langsung memberikan pengalaman kepada peserta dan segera mendiskusikan hal-hal yang dirasa menjadi kendala pada saat proses pembuatan minuman herbal. Penilaian pemateri terhadap peserta pelatihan sangat baik dikarenakan tingginya antusias peserta saat pemberian materi sampai dengan pelaksanaan pembuatan minuman herbal.

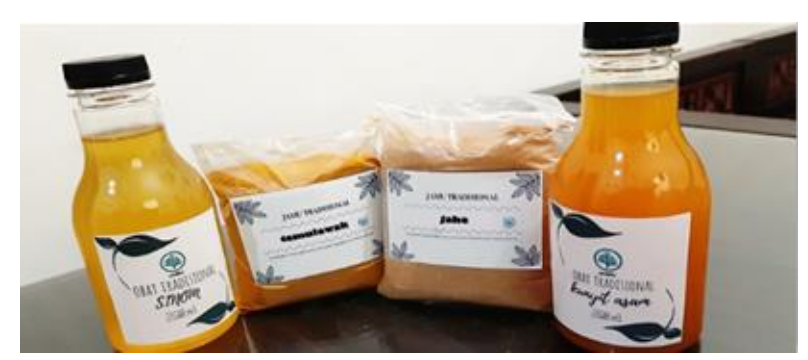

Gambar 4. Produk Minuman Herbal yang Dihasilkan

\section{KESIMPULAN}

Program pengabdian masyarakat yang dilakukan pada ibu-ibu kader puskesmas Mojolangu bidang pengobatan tradisional telah dilaksanakan dengan baik. Dengan 
kerjasama tim pengabdian yang baik maka kegiatan dapat dilakukan dan harapannya dapat memberikan manfaat bagi mitra pengabdian masyarakat dalam keberlanjutan usaha minuman herbal dengan memanfaatkan tanaman obat keluarga yang sudah dilestarikan oleh mitra. Perlu dilakukan sosialisasi secara berkelanjutan tentang pentingnya langkah preventif untuk mencegah kontaminasi produk akibat tidak higenis saat pembuatan minuman herbal. Hal ini dapat terlaksana apabila setiap kader menerapkan prinsip produksi dengan baik. Maka dari itu diharapkan mitra dapat menumbuhkan kesadaran dan kepedulian untuk menjaga agar produk yang dihasilkan dapat terjamin keamanan dan khasiatya.

\section{UCAPAN TERIMA KASIH}

Ucapan terima kasih kepada Universitas Muhammadiyah Malang yang telah membantu melancarkan kegiatan pengabdian ini. Disampaikan juga terima kasih kepada masyarakat kader puskesmas Mojolangu, Malang atas antusias dan partisipasinya dalam kegiatan ini.

\section{REFERENSI}

Andriati, A., Wahjudi, R.M.T. 2016. Tingkat Penerimaan Penggunaan Jamu Sebagai Alternatif Penggunaan Obat Modern Pada Masyarakat Ekonomi Rendah-Menengah Dan Atas. Masyarakat, Kebudayaan dan Politik. 29(3):133145.

http://dx.doi.org/10.20473/mkp.V29I32016. 133-145

Arifin, Z., Yuliawati, F., Syafrawi. 2017. IbM Home Industri Jamu Tradisional Madura Untuk Meningkatkan Daya Saing Di Kabupaten Pamekasan. Jurnal Pengabdian Masyarakat JDinamika. 1(2):92-102. https://doi.org/10.25047/jdinamika.v1i2.283

Ingratubun, E.S., Sombolayuk, W. 2018. Ekonomi Politik Dalam Pembangunan Industrialisasi Global.
Simak: Jurnal Sistem Informasi, Manajemen, dan Akuntansi.

16(8):167-181.

https://doi.org/10.35129/simak.v16i02.41

Ismono, Suyatno, Hidajati, N. 2018. Pelatihan Pembuatan Serbuk Minuman Herbal Instan Untuk Warga Desa Jajar, Kecamatan Talun, Kabupaten Blitar. Jurnal Abdi: Media pengabdian kepada masyarakat. 3(2):76-83. http://dx.doi.org/10.26740/ja.v3n2.p76-83

Jo, N. 2016. Studi Tanaman Khas Sumatera Utara Yang Berkhasiat Obat. Jurnal Farmanesia. 3(1):11-21.

Jumiarni, W.O., Komalasari, O. 2017. Eksplorasi Jenis dan Pemanfaatan Tumbuhan Obat pada Masyarakat Suku Muna di Permukiman Kota Wuna. Majalah Obat Tradisional. 22(1):45-56. https://doi.org/10.22146/tradmedj.24314

Khamidah, A., Antarlina, S.S., Sudaryono, T. 2017. Ragam Produk Olahan Temulawak Untuk Mendukung Keanekaragaman Pangan. Jurnal Penelitian dan Pengembangan Pertanian. 36(1):112.

http://dx.doi.org/10.21082/jp3.v36n1.2017.p $1-12$

Moehady, B.I. 2015. Serbuk Temulawak Sebagai Bahan Baku Minuman. Prosiding Industrial Research Workshop and National Seminar. 6:55-60. https://doi.org/10.35313/irwns.v6i0.245

Mukhlish, B. 2018. Kolaborasi antara Universitas, Industri dan Pemerintah dalam Meningkatkan Inovasi dan Kesejahteraan Masyarakat: Konsep, Implementasi dan Tantangan. Jurnal Administrasi Bisnis Terapan. 1(1):31-43. https://doi.org/10.7454/jabt.vli1.27

Rachmawati, I.K., Isvandiari, A., Andini, T.D., Hidayatullah, S. 2018. PKM. Peningkatan Usaha Jamu Saritoga Ukm "Prayogo" dan Karang Taruna "Bhakti" Dusun Lopawon Desa Kebobang Wonosari Kabupaten Malang. JAPI (Jurnal Akses Pengabdian Indonesia). 3(2):70-76. https://dx.doi.org/10.33366/japi.v3i2.1016

Septiana, A. 2019. Tinjauan Perilaku Konsumtif Masyarakat Pesisir Dalam Islam (Studi Kasus pada Masyarakat Pesisir Desa Bandaran, Kecamatan Tlanakan, Kabupaten Pamekasan). Dinar: Jurnal Ekonomi dan 
Keuangan $\quad$ Islam.
https://doi.org/10.21107/dinar.v5i1.4639-107.

Sukmawati, W., Merina, M. 2019. Pelatihan Pembuatan Mipelatihan Pembuatan Minuman Herbal Instan Untuk Meningkatkan Ekonomi Warganuman Herbal Instan Untuk Meningkatkan Ekonomi Warga. Jurnal Pengabdian Kepada Masyarakat. 25(4):210-215. http://dx.doi.org/10.24114/jpkm.v25i4.1487 4 